\title{
Probiotic Potential of Pediococcus acidilactici and Enterococcus faecium Isolated from Indigenous Yogurt and Raw Goat Milk
}

\author{
Shovon Lal Sarkar ${ }^{1}$, Md. Iqbal Hossain ${ }^{1,3}$, Sharmin Akter Monika ${ }^{1}$, Santonu Kumar Sanyal ${ }^{1,4}$, Pravas Chandra Roy ${ }^{1}$, \\ Md. Anwar Hossain ${ }^{2}$, and lqbal Kabir Jahid ${ }^{1 *}$ \\ ${ }^{1}$ Department of Microbiology, Jashore University of Science and Technology, Jashore 7408, Bangladesh \\ ${ }^{2}$ Department of Microbiology, University of Dhaka, Dhaka 1000, Bangladesh \\ ${ }^{3}$ Department of Food Science and Technology, Chung-Ang University, Anseong 17546, Republic of Korea \\ ${ }^{4}$ Department of Microbiology, Jagannath University, Dhaka 1100, Bangladesh
}

Received: December 15, 2019 / Revised: March 6, 2020 / Accepted: March 9, 2020

\begin{abstract}
Probiotics are live microorganisms that, when administered in adequate amounts, confer health benefits to the host. This study was conducted for the isolation of potential lactic acid bacteria (LAB) with probiotic properties from goat milk and yogurt. Several tests were conducted in vitro using the standard procedures for evaluating the inhibitory spectra of LAB against pathogenic bacteria; tolerance to NaCl, bile salt, and phenol; hemolytic, milk coagulation, and bile salt hydrolase activities; gastrointestinal transit tolerance; adhesion properties; and antibiotic susceptibility. Among 40 LAB strains screened according to culture characteristics, five isolates exhibited antagonistic properties. Three were identified as Pediococcus acidilactici, and two were identified as Enterococcus faecium, exploiting 16S rRNA gene sequencing. All the isolates succeeded in the gastrointestinal transit tolerance assay and successively colonized mucosal epithelial cells. Based on the results of these in vitro assays, both $P$. acidilactici and $E$. faecium can be considered as potential probiotic candidates.
\end{abstract}

Keywords: Probiotic, antagonistic assay, Pediococcus acidilactici, Enterococcus faecium, goat milk, 16S rRNA

\section{Introduction}

Probiotic is defined as live microorganisms posses auspicious health benefit when administered in sufficient amounts to the host [1]. Promising probiotic strains constitute a significant part of lactic acid bacteria (LAB) group and these probiotics are persistent in milk and milk-derived products [2] and are also omnipresent in the animal, human gastrointestinal tracts, traditional fermented foods as well as overall environment [3]. LAB, predominant in raw goat milk, when picked, contributes

\section{*Corresponding author}

Tel: +88-01709-818178, Fax: +88-02421-61199

E-mail: ikjahid_mb@just.edu.bd

(c) 2020, The Korean Society for Microbiology and Biotechnology to the highest functional value [4]. Moreover, the promotion of human health via functional food like probiotic milk, yogurt, cheese is in high demand [5]. To get the medicinal benefit from processed foods, the numerical value of probiotic bacteria should be within a limit of $10^{6}-10^{7} \mathrm{CFU} / \mathrm{g}$ or $10^{8}-10^{9} \mathrm{CFU} / 100 \mathrm{~g}$ or $100 \mathrm{ml}$ of daily food consumption [6]. Enterococci belong to the commensal microbiota of human and animals and commonly occur in dairy products, fish and seafood [7]. Seemingly, Enterococci play a vital role in various fermented foods, including dairy and vegetable products through proteolysis, lipolysis, exopolysaccharide production and citrate breakdown [8]. Some Enterococci produce a wide range of bacteriocins called enterocins, considered to use as natural additives for preserving food by extending their 
shelf life and inhibiting the proliferation of bacteria in food products [9]. Pediococcus acidilactici also has several exciting properties including resistance to heat, $\mathrm{pH}$, cold, proteolytic treatments, and the capacity for the production of pediocin as an antimicrobial peptide with anti-listerial activity, which makes it enthralling as a food bio-preservative [10].

Probiotics possess inhibitory activities on the growth of pathogenic bacteria. The altered $\mathrm{pH}$ values by producing organic acids, producing bacteriocin, producing hydrogen peroxide, and competitive adhesion to the epithelium could result in the inhibitory effect which exerts probiotic activity [11]. The effective probiotic microorganisms should be safe, viable, antimicrobial characteristics, acid, bile salt, and gastric juices tolerant, able to survive through the gastrointestinal tract, adherence to intestinal epithelial cells [12]. Moreover, the capability of a bacterial strain to adhere to the digestive tract is a prerequisite for colonization [13]. In the recent past, various investigations on lactic acid bacteria have reported a wide range of health stimulating properties inducing the host gut microbial balance [14, 39].

Therefore, the present study aims at isolation, characterization and, identification of probiotics from natural goat milk and milk products with an assessment of these strains as a potential probiotic candidate.

\section{Materials and Methods}

\section{Isolation of lactic acid bacteria (LAB)}

Five raw Black Bengal goat milk samples were collected from lactating goats, and five yogurt samples were purchased from different dairy shops in Jashore District, Bangladesh. After aseptic collection, the samples were transported in a transportation box and stored at four-degree centigrade $\left(4^{\circ} \mathrm{C}\right)$ to protect deterioration and contamination.

For isolation, sample $(10 \mathrm{ml}$ or $10 \mathrm{~g})$ were homogenized in $90 \mathrm{ml}$ MRS (de Man, Rogosa and Sharpe agar; Himedia, India) broth for enrichment at $37^{\circ} \mathrm{C}$ for $24 \mathrm{~h}$ in shaking incubator (Model:SI-100R, Korea). After enrichment streaking was carried out on MRS (Himedia) agar media following a $48 \mathrm{~h}$ incubation period at $37^{\circ} \mathrm{C}$. After incubation, representative colonies were randomly purified by successive re-streaking. Gram-positive and catalase-negative isolates were preliminarily considered as possible LAB. Finally, pure cultures of LAB isolates were stored at $-80^{\circ} \mathrm{C}$. The strains were further characterized for probiotics properties and safety issues.

\section{Identification of lactic acid bacteria}

Based on antagonistic activity, five isolates were used for 16S rRNA gene sequencing similarity and phylogenetic analysis. In brief, from fresh bacterial culture $\left(<10^{9}\right.$ cells $\left./ \mathrm{ml}\right)$, the chromosomal DNA of the isolates were extracted using ATP ${ }^{\mathrm{TM}}$ Genomic DNA Mini Kit (ATP Biotech Inc., USA). The 16S rRNA gene was further amplified using the universal primers: $27 \mathrm{~F}$ (5'AGAGTTTGATCCTGGCTCAG-3'), 1492R (5'-GGTTACCTTGTTACGACTT-3') by polymerase chain reaction [15]. The PCR reaction was conducted at $96{ }^{\circ} \mathrm{C}$ for $5 \mathrm{~min}$ and then continued with the denaturation at $94^{\circ} \mathrm{C}$ for $1 \mathrm{~min} 30 \mathrm{~s}$, annealing at $55^{\circ} \mathrm{C}$ for $1 \mathrm{~min}$ and extension at $72^{\circ} \mathrm{C}$ for $1 \mathrm{~min} 30 \mathrm{~s}$ for a total of 35 cycles followed by a final extension of $10 \mathrm{~min}$ at $72^{\circ} \mathrm{C}$. The $16 \mathrm{~S}$ rRNA gene PCR products of the isolates were purified with the Wizard PCR SV Gel and PCR Clean-Up System kit (Promega, USA) and sequenced (ABI Prism 3130 Genetic Analyzer, USA) using forward $27 \mathrm{~F}$ and reverse $1492 \mathrm{R}$ primers. Partial sequences were combined via the SeqMan Genome Assembler (DNAstar, USA) and were compared to the GenBank database of the National Center for Biotechnology Information (NCBI) (http:// www.ncbi.nlm.nih.gov/GenBank) by Basic Local Alignment Search Tool (BLAST) to identify close phylogenetic relatives. Multiple sequence alignment of the retrieved reference sequences from NCBI was performed using ClustalW [16] software and was exported to the Molecular Evolutionary Genetics Analysis (MEGA.4) [17] program for phylogenetic tree construction using the Neighbor-joining algorithm and selecting 1000 bootstrap replication. Isolates sequences used for the cladogram construction were deposited in GenBank with accession numbers (MH656745.1-MH656749.1).

\section{Determination of the properties of probiotic potentials Determination of antagonistic activity of isolated LAB.}

Once pure cultures were obtained, antagonistic activity was determined against different enteric pathogens. Eight different strains including Salmonella Typhimurium ATCC 14028, Salmonella Enteritidis ATCC 13098, Escherichia coli ATCC 10536, E. coli O157:H7 
ATCC 43894, Enterococcus faecalis ATCC 29212, Listeria monocytogenes ATCC 19113, Vibrio cholerae (O1), Shigella flexneri weres elected for antagonistic assay. Overnight well-grown cultures of the isolates were centrifuged (DAIHAN Scientific Co. Ltd; Model: CF-10, Korea) at 12000 revmin $^{-1}$ for $14 \mathrm{~min}$. The resultant Cellfree Culture Supernatant (CFCS) was filtered by using $0.2(\mathrm{~mm})$ Chromafil $^{\circledR}$ syringe filters (MACHEREYNAGEL, Germany).

Antagonistic activity was performed by agar well diffusion method described by Tulumoglu et al. [18]. Then actively growing overnight cultured test strains $\left(\sim 10^{8}\right.$ $\mathrm{CFU} / \mathrm{ml}$ ) (OD 0.125 in $550 \mathrm{~nm}$ ) was swabbed followed by placing $100 \mu \mathrm{l}$ CFCS into $6 \mathrm{~mm}$ wells of agar and incubated at $37^{\circ} \mathrm{C}$ for $24 \mathrm{~h}$ and the zone of inhibition was measured.

Effect of bile salts on LAB growth. Tolerance to bile was assayed by growing the isolates in broth, following the procedure reported by Ramos et al. [19]. The growth rates of the strains were estimated in MRS broth medium supplemented with $0.3 \%$ bile salt. Overnight grown cultures were inoculated (1\%) into the liquid medium and incubated at $37^{\circ} \mathrm{C}$ for up to $4 \mathrm{~h}$. Absorbance at $600 \mathrm{~nm}$ was measured every hour of incubation through UV-VIS spectrophotometer (Model: T60UV, PG Instruments Ltd., UK).

Qualitative bile salt hydrolase (BSH) activity test. To perform qualitatively salt hydrolase activity of selected isolates were performed according to Huang et al. [20]. For this test, LAB isolates were streaked on MRS agar which contains $0.5 \%(\mathrm{w} / \mathrm{v})$ taurodeoxycholic acid sodium salt (TDCA; Sigma, USA) and 0.037\% calcium chloride, and incubated anaerobically at $37^{\circ} \mathrm{C}$ for $72 \mathrm{~h}$ in an anaerobic jar. Precipitated zones of hydrolyzed salts around the colonies were counted as a positive result.

Milk coagulation test. Milk coagulation test was performed according to Chettri and Tamang [21]. After overnight $1.5 \mathrm{ml}$ of LAB culture was centrifuged (12000 $\times g, 4^{\circ} \mathrm{C}, 7 \mathrm{~min}$ ) and harvested cells were washed two times with PBS ( $\mathrm{pH}$ 7.2, 0.1 phosphate buffer, $0.8 \%$ $\mathrm{NaCl}$ ) and mixed with $15 \mathrm{ml}$ of sterilized cow milk. Afterward, the mixture was incubated overnight at $37^{\circ} \mathrm{C}$ and the formation of clot was observed.
$\mathrm{NaCl}$ concentration effect on LAB growth. The effect of $\mathrm{NaCl}$ on $\mathrm{LAB}$ growth was conducted according to the methodology defined by Abbasiliasi et al. [22] with little modification. For determining $\mathrm{NaCl}$ tolerance, all the isolates were grown in MRS broth with adding a different concentration of $\mathrm{NaCl}(1-10 \% \mathrm{w} / \mathrm{v})$ and bromocresol purple. The broth was inoculated with $1 \%$ (v/v) overnight culture of the isolates and incubated at $37^{\circ} \mathrm{C}$ for $24 \mathrm{~h}$. After incubation, their growth was evaluated, determined by a color change from purple to yellow.

Effect of temperature on LAB growth. For performing the effect of temperature on selected LAB isolates, freshly grown overnight cultures were inoculated $(1 \% \mathrm{v} / \mathrm{v})$ into MRS broth and incubated for $24 \mathrm{~h}$ at varying temperature ranges $\left(4^{\circ} \mathrm{C}, 25^{\circ} \mathrm{C}, 37^{\circ} \mathrm{C}, 45^{\circ} \mathrm{C}\right.$, or $\left.55^{\circ} \mathrm{C}\right)$ [22].

Phenol concentration effect on LAB growth. Phenol tolerance experiments were performed by inoculating $1 \%$ of fresh overnight cultures into MRS broth containing different concentration (0.1-0.4\% (w/v) of phenol described by Aswathy et al. [23]. After overnight incubation at $37^{\circ} \mathrm{C}$, the concentration of bacterial cells was measured using UV-VIS spectrophotometer at the absorbance (A) at $600 \mathrm{~nm}$.

Adhesion assay to ileum mucosal epithelium. Chicken colonization studies were performed as described previously. Flanagan et al. [24] with minor modification. The intestine was dissected from the chicken and washed with Phosphate Buffer Saline (Sigma-Aldrich) to remove the ingesta from the mucosal surface. It washed for several times with cold phosphate buffer saline and cut into small pieces $\left(1 \times 1 \mathrm{~cm}^{2}\right)$, that soaked into LAB suspension $\left(\sim 10^{8} \mathrm{CFU} / \mathrm{ml}\right)$ with the intention to incubation at $37^{\circ} \mathrm{C}$ for $90 \mathrm{~min}$. A single cutting piece of soaked intestine was removed at different time intervals $0,30,60$, and $90 \mathrm{~min}$ to check the adhesion capability by viable count method. Then the small piece of intestine was washed with PBS to remove the non-adhesive bacteria from the surface, grinded and mixed it in a small volume of PBS to make a solution. The solution then serially diluted and $0.1 \mathrm{ml}$ of it was transferred on MRS agar plates. Bacterial colonies were calculated following the incubation period of $24 \mathrm{~h}$ at $37^{\circ} \mathrm{C}$. 
In vitro gastrointestinal transit tolerance assay. According to Huang and Adams [25], simulated gastric juice was prepared by suspending glucose $(\mathrm{NaCl} 2.05 \mathrm{~g} / \mathrm{l}$, $\left.3.5 \mathrm{~g} / \mathrm{l}, \mathrm{CaCl}_{2} 0.11 \mathrm{~g} / \mathrm{l}, \mathrm{KH}_{2} \mathrm{PO}_{4} 0.60 \mathrm{~g} / \mathrm{l}, \mathrm{KCl} 0.37 \mathrm{~g} / \mathrm{l}\right)$, adjusted to $\mathrm{pH}$ 2.0. Then the gastric juice solution was supplemented with $0.05 \mathrm{~g} / \mathrm{l}$ bile (Liofilchem, Italy), $0.1 \mathrm{~g} / \mathrm{l}$ lysozyme (Ameresco, USA), and $13.3 \mathrm{mg} / \mathrm{l}$ pepsin (LobaloChemie) as stock solutions prior to analysis. A single colony of probiotic LAB was impregnated into MRS broth and incubated whole night at $37^{\circ} \mathrm{C} .1 \mathrm{ml}$ sample was taken and centrifuged $\left(7000 \times g, 4^{\circ} \mathrm{C}, 15 \mathrm{~min}\right)$. After two times washing of pellet in sterile Phosphate-Buffer Solution and re-suspended in $5 \mathrm{ml}$ of simulated gastric juice (with \& without lysozyme), it was further incubated at $37^{\circ} \mathrm{C}$ for 90 min with constant stirring by using shaking incubator (Model: SI-100R, Korea). After that, 1 $\mathrm{ml}$ of different ranged diluted sample was spread on MRS agar plates at different time interval (0, 30,60, and $90 \mathrm{~min}$ ). The viability of cell determined using the plate count method, and the results were expressed as log $\mathrm{CFU} / \mathrm{ml}$.

\section{Safety analysis of the LAB strains}

Haemolytic activity assay. Freshly grown bacterial cultures were transferred on blood base agar (Oxoid,UK) plates by streaking (containing $5 \% \mathrm{v} / \mathrm{v}$ of human blood) and incubated at $37^{\circ} \mathrm{C}$ for $24 \mathrm{~h}$. The presence of clear zone ( $\beta$-haemolysis), green zone ( $\alpha$-haemolysis) or the absence of zone ( $\gamma$-haemolysis) around the colonies indicated the haemolytic activity [26]. $\alpha$ and $\gamma$-haemolysis were regarded as non-haemolytic, while blood lyses zones around the colonies were considered as hemolytic ( $\beta$-hemolysis).

Antibiotic susceptibility assay. Antibiogram of the strains followed the antibiotic disc diffusion method [22]. The antibiotic discs (Hi-media) tested were used at following concentrations: streptomycin $(10 \mu \mathrm{g})$, gentamycin $(10 \mu \mathrm{g})$, chloramphenicol (30 $\mu \mathrm{g})$, vancomycin (30 $\mu \mathrm{g})$, ciprofloxacin $(10 \mu \mathrm{g})$, amikacin $(30 \mu \mathrm{g})$, Azithromycin $(15 \mu \mathrm{g})$, ceftriaxone $(30 \mu \mathrm{g})$, norfloxacin $(30 \mu \mathrm{g})$, cefaclor $(30 \mu \mathrm{g})$ chosen recommended by the European Food Safety Author (EFSA, 2012). After overnight growth in MRS broth at $37^{\circ} \mathrm{C}$ and diluted to match with $0.5 \mathrm{McFar}$ land standards, the diluted culture (approximate $10^{7}$ viable cells) was cotton swabbed onto Mueller-Hinton
Agar (MHA) medium (Liofilchem), and antibiotic discs were applied onto the surface. After incubated at $37^{\circ} \mathrm{C}$ for $24 \mathrm{~h}$, the zone diameters $(\mathrm{mm})$ were measured (including the antibiotic disc) to determine susceptibility based on the CLSI standard (2012).

Statistical analysis. Using GraphPad Prism Version 6 (GraphPad Software, USA) the data analyses were performed. To determine remarkable effects, all of the experiments were independently repeated three times. One way ANOVA and Two-way ANOVA (ANOVA, Analysis of variance) used to study the significant difference between the mean of various experiments and a value, $p<0.05$ has been considered as a significant effect.

\section{Results and Discussion}

\section{Isolation and identification of LAB}

Milk and dairy products are used as the source of probiotics from the beginning of probiotics history. From 10 goat milk and traditional yogurt samples, $40 \mathrm{LAB}$ strains (20 from goat milk and 20 from yogurt) were primarily isolated from the selective MRS agar media. Use of yogurt for its health benefiting nutrients and good probiotics bacteria makes it an ideal food throughout the world. Many researchers use probiotics as alternatives to antibiotics for the treatment of digestive tract diseases. Prior to identification, the isolates were primarily screened for anti-pathogen activity by using cell free culture supernatant. Among the 40 strains, five of them namely B.1, 12/1, 12/3, 13/1 and 14/1 showed antimicrobial activities against six enteric pathogens (out of eight tested pathogens) (Table 1). Additionally, three isolates showed the antimicrobial activity against Shigella flexneri. except 12/1 and 14/1. Interestingly, all the three isolates were identified as $P$. acidilactici (B.1, 12/3, 13/1). On the other hand, only the $12 / 1$ isolates cell-free supernatant demonstrates moderate antimicrobial activity (inhibition zone $<15 \mathrm{~mm}$ ) against Vibrio cholerae 01. Greater antimicrobial activity against Enterococcus faecalis ATCC 29212 by the isolates named 12/3 and 13/1 (inhibition zone $>16 \mathrm{~mm}$ ) was observed. Out of 20 primarily selected isolates of goat milk, only B1 showed antimicrobial activity. Goat milk is a highly nutritious, easily absorbable probiotic riched ideal food [27]. Its nutritional quality, bacterial diversity and other 
Table 1. Determination of antibacterial activity of cell free culture supernatant (CFCS) of isolates against target pathogens. Lactobacillus acidophilus KACC 12419 used as positive control. Values of zone diameter represent the mean \pm SD.

\begin{tabular}{|c|c|c|c|c|c|c|}
\hline \multirow[b]{2}{*}{ Microorganisms } & \multicolumn{5}{|c|}{ Isolates designation and zone diameter (mm) } & \multirow[b]{2}{*}{$\begin{array}{l}\text { Lactobacillus } \\
\text { acidophilus } \\
\text { KACC } 12419\end{array}$} \\
\hline & B1 & $12 / 1$ & $12 / 3$ & $13 / 1$ & $14 / 1$ & \\
\hline Salmonella Typhimurium ATCC 14028 & $14 \pm 0$ & $14.5 \pm 0.7$ & $14.3 \pm 0.3$ & $15 \pm 0$ & $15.1 \pm 0.1$ & $15.3 \pm 0$ \\
\hline Salmonella Enterititidis ATCC 13098 & $13.5 \pm 0.7$ & $13.5 \pm 0.7$ & $13.5 \pm 0.7$ & $14.25 \pm 0.3$ & $14 \pm 0$ & $14 \pm 0.2$ \\
\hline Escherichia coli ATCC 10536 & $14.5 \pm 0.7$ & $15.05 \pm 0.07$ & $15.25 \pm 0.3$ & $15 \pm 0$ & $15 \pm 0$ & $21 \pm 0$ \\
\hline E. coli 0157:H7 ATCC 43894 & $14.25 \pm 0.3$ & $14 \pm 0$ & $13.5 \pm 0.7$ & $15 \pm 0.7$ & $15.1 \pm 0.1$ & $15 \pm 0.1$ \\
\hline Enterococcus faecalis ATCC 29212 & $14 \pm 0$ & $15 \pm 0$ & $16.25 \pm 0.3$ & $16.25 \pm 0.3$ & $15.15 \pm 0.2$ & $13 \pm 0.2$ \\
\hline Listeria monocytogenes ATCC 19113 & $14 \pm 0$ & $13.25 \pm 0.3$ & $13.25 \pm 0.3$ & $15.25 \pm 0.3$ & $14.15 \pm 0.2$ & $14 \pm 0$ \\
\hline Vibrio cholerae 01 & 0 & $13.5 \pm 0.7$ & 0 & 0 & 0 & 0 \\
\hline Shigella flexneri & $12 \pm 0$ & 0 & $12.5 \pm 0.7$ & $13 \pm 0$ & 0 & 0 \\
\hline
\end{tabular}

health-benefiting factors made its as an ideal source for probiotics. Probiotics from Goat milk proved potential as a probiotic reported by de Moraes et al. [28] but this is the first report of probiotic isolation from the Black Bengal goat. Among the five isolates, only the B1 (P. acidilactici) is isolated from the goat milk, thereby it can be said that the raw goat milk is a good source of probiotics bacteria. But, yogurt may contain a higher ratio (4:20) with diversified bacterial spp. than the goat milk (1:20).

Selected five isolated strains were gram-positive, catalase negative and cocci shaped. Their final identification procedure followed the 16S rRNA sequencing similarity and phylogenetic analysis. By using BLASTN, the nucleotide sequences of these PCR products (1500 bp) were compared with the database of GenBank. The isolates B.1, 12/3, 13/1 showed $\sim 98 \%$ similarity with $P$. acidilactici and 12/1, 14/1 showed $\sim 98 \%$ similarity with $E$. faecium. After 16S rRNA sequencing, the sequences were submitted to GenBank for their accession number (MH656749.1, MH656748.1, MH656747.1 for $P$. acidilactici and MH656746.1, MH656745.1 for E. faecium. Phylogenetic tree construction was made using MEGA software and the Neighbor-joining algorithm linked to 1000 bootstrap replication (Fig. 1).

\section{Determination of potential probiotic properties}

Effect of bile salts on LAB growth. Bile salts pose a deleterious effect on living cells by damaging their cell membrane structure. According to Argyri et al. [29], resistance to bile salt is essential properties for probiotic bacteria that can persist and colonize in the small intestine of the host to provide a beneficial effect. A strain can

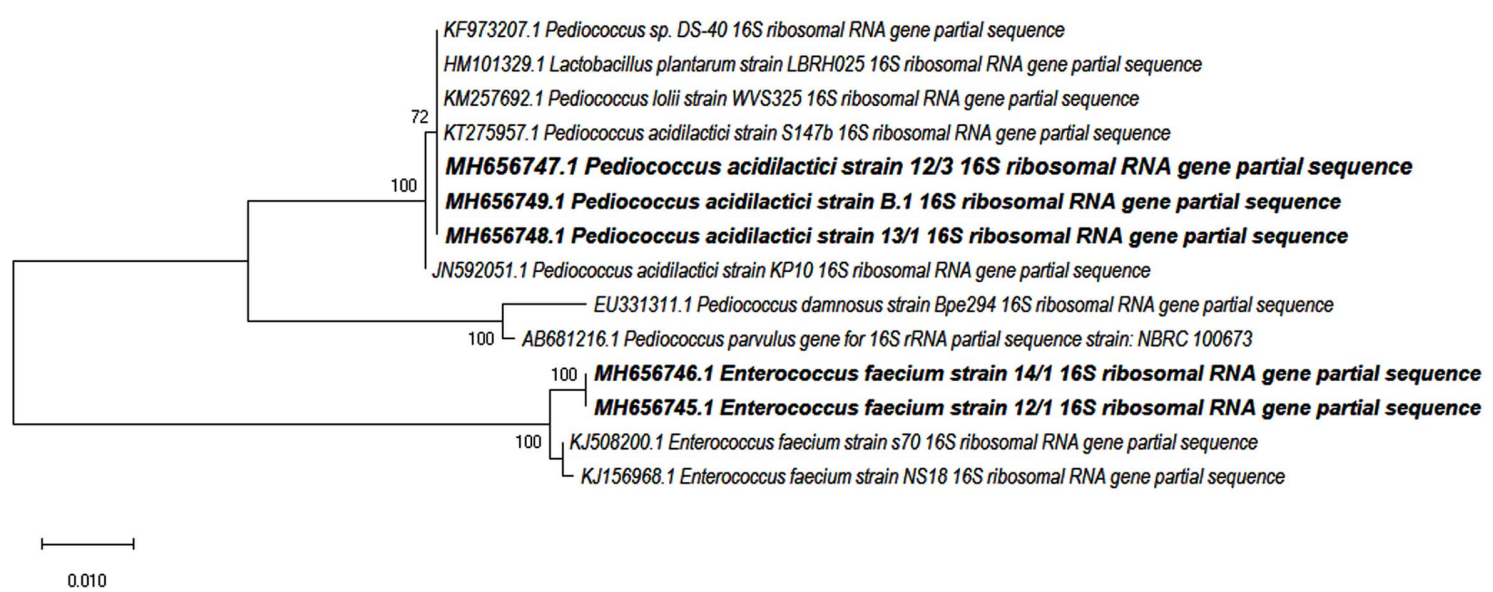

Fig. 1. A neighbor-joining phylogenetic relationship with related species based on partial 16S rRNA gene sequence analysis. 
A. Bile salt tolerance effect $(0.3 \%)$

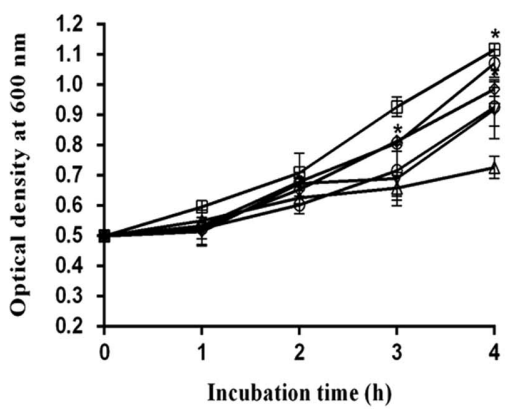

B. Phenol Tolerance effect

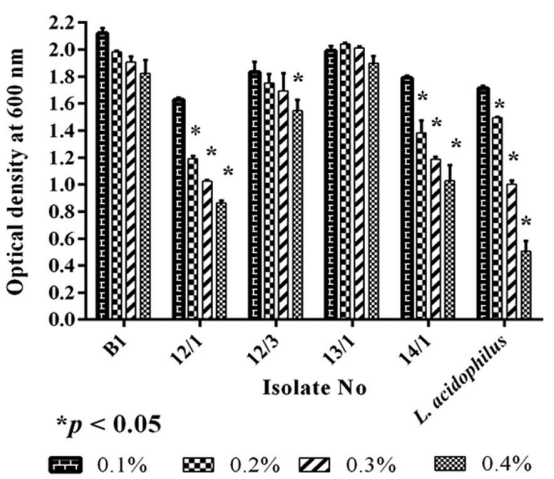

C. Adherence test

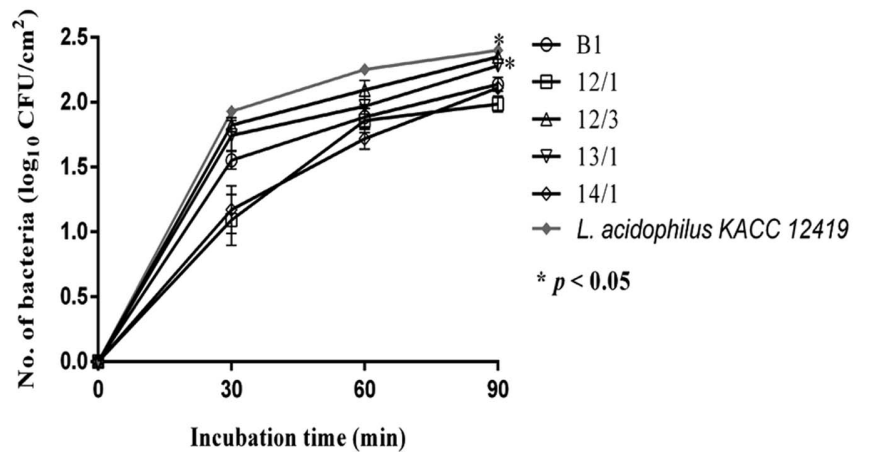

Fig. 2. (A) Tolerance of five isolated LAB strains and one positive control Lactobacillus acidophilus KACC 12419 in MRS broth supplemented with $\mathbf{0 . 3 \%}$ bile salt. The results are expressed as mean \pm SD of three independent experiments. Statistical significance was determined with the help of one way ANOVA. ${ }^{*} p<0.05,{ }^{* *} p<0.01$, ${ }^{* *} p<0.001$, (B) Tolerance of the isolates to $(0.1 \%$ $0.4 \%)$ phenol. The results are expressed as mean \pm SD of three independent experiments. Statistical significance was determined with the help of one way ANOVA. ${ }^{*} p<0.05,{ }^{* *} p<0.01,{ }^{* *} p<0.001$, (C) Adherence effect of the isolated probiotic candidates to ileum mucosal epithelium. The results are expressed as mean \pm SD of three independent experiments. Statistical significance was determined with the help of one way ANOVA. ${ }^{*} p<0.05,{ }^{* *} p<0.01,{ }^{* * *} p<0.001$.

be only considered as probiotic when it will be able to survive at $0.15-0.3 \%$ bile salt, which resembles the human intestinal bile salt condition [30]. According to the results, all five isolates along with Lactobacillus acidophilus KACC 12419 survived at $0.3 \%$ bile salt concentration but there growth rate varied over time. $P$. acidilactici of goat milk isolates (B1) showed lowest growth $(\mathrm{OD}=0.7)$ after $4 \mathrm{~h}$ of incubation at $0.3 \%$ bile salt. On the otherhand $P$. acidilactici (12/3) from yogurt showed the highest cell concentration $(\mathrm{OD}=1.1)$ compared to the initial bacterial number $(\mathrm{OD}=0.5)($ Fig. $2 \mathrm{~A})$.

Bile salt hydrolase (BSH) activity is another vital property for probiotics selection, which indicates the survival at a toxic level of bile salts [31]. All probiotic isolates that showed antagonistic activity against pathogens also displayed BSH activity (Table 2), which infers that iso- lates survived under toxicity of these salts and deconjugation of TDCA, and may help in their intestinal colonization which is a significant finding of our study as all isolates showed BSH activity. Unless proper colonization, the probiotics can not confer its beneficiary effect to the host. Similar results also reported by other authors, where the isolates which were positive for BSH activity showed greater tolerance to bile salt than the $\mathrm{BSH}$ negative strains [32].

Milk coagulation and hemolytic activities. The results of the assessment of milk coagulation activity are summarized in Table 2. Due to the association of lactic acidforming bacteria, all probiotic isolates coagulate the milk. It not only converted the milk into yogurt form but also produced a good aroma. 
Table 2. Physiological characteristics-growth in the presence of $\mathrm{NaCl}$ and temperature variation, bile salt hydrolase (BSH) activity, milk coagulation, and haemolytic activity assay using the standard procedures.

\begin{tabular}{|c|c|c|c|c|c|c|}
\hline \multirow{2}{*}{$\begin{array}{c}\text { Physiological characteristic } \\
\text { Growth in MRS broth: }\end{array}$} & \multicolumn{6}{|c|}{ Isolates name } \\
\hline & B1 & $12 / 1$ & $12 / 3$ & $13 / 1$ & $14 / 1$ & $\begin{array}{l}\text { Lactobacillus } \\
\text { acidophilus } \\
\text { KACC } 12419\end{array}$ \\
\hline With $1 \% \mathrm{NaCl}$ & + & + & + & + & + & + \\
\hline With $2 \% \mathrm{NaCl}$ & + & + & + & + & + & + \\
\hline With 3\% NaCl & + & + & + & + & + & + \\
\hline With $4 \% \mathrm{NaCl}$ & + & + & + & + & + & + \\
\hline With $5 \% \mathrm{NaCl}$ & + & + & + & + & + & + \\
\hline With $6 \% \mathrm{NaCl}$ & + & + & + & + & + & + \\
\hline With $7 \% \mathrm{NaCl}$ & - & - & - & - & - & + \\
\hline With $8 \% \mathrm{NaCl}$ & - & - & - & - & - & - \\
\hline With $9 \% \mathrm{NaCl}$ & - & - & - & - & - & - \\
\hline With $10 \% \mathrm{NaCl}$ & - & - & - & - & - & - \\
\hline At $4{ }^{\circ} \mathrm{C}$ & - & - & - & - & - & - \\
\hline At $25^{\circ} \mathrm{C}$ & + & + & + & + & + & + \\
\hline At $37^{\circ} \mathrm{C}$ & + & + & + & + & + & + \\
\hline At $45^{\circ} \mathrm{C}$ & + & + & + & + & + & + \\
\hline At $55^{\circ} \mathrm{C}$ & - & - & + & + & - & - \\
\hline BSH (Bile salt Hydrolase) activity & + & + & + & + & + & + \\
\hline Milk coagulation & + & + & + & + & + & + \\
\hline
\end{tabular}

To be considered as probiotics, unlike the pathogenic one, the bacteria must be non-hemolytic [33]. Generally, LAB members do not carry out hemolytic activity In our experiments, all the examined strains were $\gamma$-haemolytic (non-haemolytic) when grown in blood agar (Table 2). This indicates that the selected LAB strains are safe for consumption.

Effect of $\mathrm{NaCl}$ concentration on growth pattern. Cell physiology and metabolism are affected by the turgor pressure when bacteria grow in high salt concentration [34]. Table 2 illustrates the growth performance of the probiotics on different $\mathrm{NaCl}$ concentrations. All probiotic isolates were capable to grow in $1-6 \% \mathrm{NaCl}$ concentration, but their growth was inhibited by $7-10 \%$. Salt tolerance ability varies among strain to strain and source of the probiotics. There are reports of LAB isolated from Bangladesh that can tolerate 4-8\% NaCl [35]. Whereas LAB isolated from India showed similar tolerance ability [36].
Effect of temperature on growth. LAB can be differentiated by the growth in optimum temperature [37]. Our results indicated that $P$. acidilactici can grow at a wide range of temperatures $\left(25-55^{\circ} \mathrm{C}\right)$ except for the goat milk isolates (Temperature ranges: $25-45^{\circ} \mathrm{C}$ ). but for $E$. faecium the temperature ranges was $25-45^{\circ} \mathrm{C}$. The effect of temperature on growth is shown in Table 2. Although, all the probiotic isolates were able to grow at $25^{\circ} \mathrm{C}, 37^{\circ} \mathrm{C}$ and $45^{\circ} \mathrm{C}$; however, they cannot grow at $4{ }^{\circ} \mathrm{C}$. From the data, we can say that our isolates were mesophilic and thermotolerant. Isolation of thermotolerant probiotics from yogurt is rare, where Pundir et al. [36] isolated probiotic bacteria minimum and maximum growth temperature was $25^{\circ} \mathrm{C}$ and $40^{\circ} \mathrm{C}$ respectively.

Effect of phenol on growth. All the isolates survival ability decrease when the concentration of phenol increases from $0.1 \%$ to $0.4 \%$ except for $13 / 1$. Isolate $13 / 1$ (P. acidilactici) tolerate $0.2 \%$ and $0.3 \%$ phenol better than $0.1 \%$ and $0.4 \%$ phenol. Fig. 3 showed that all the 

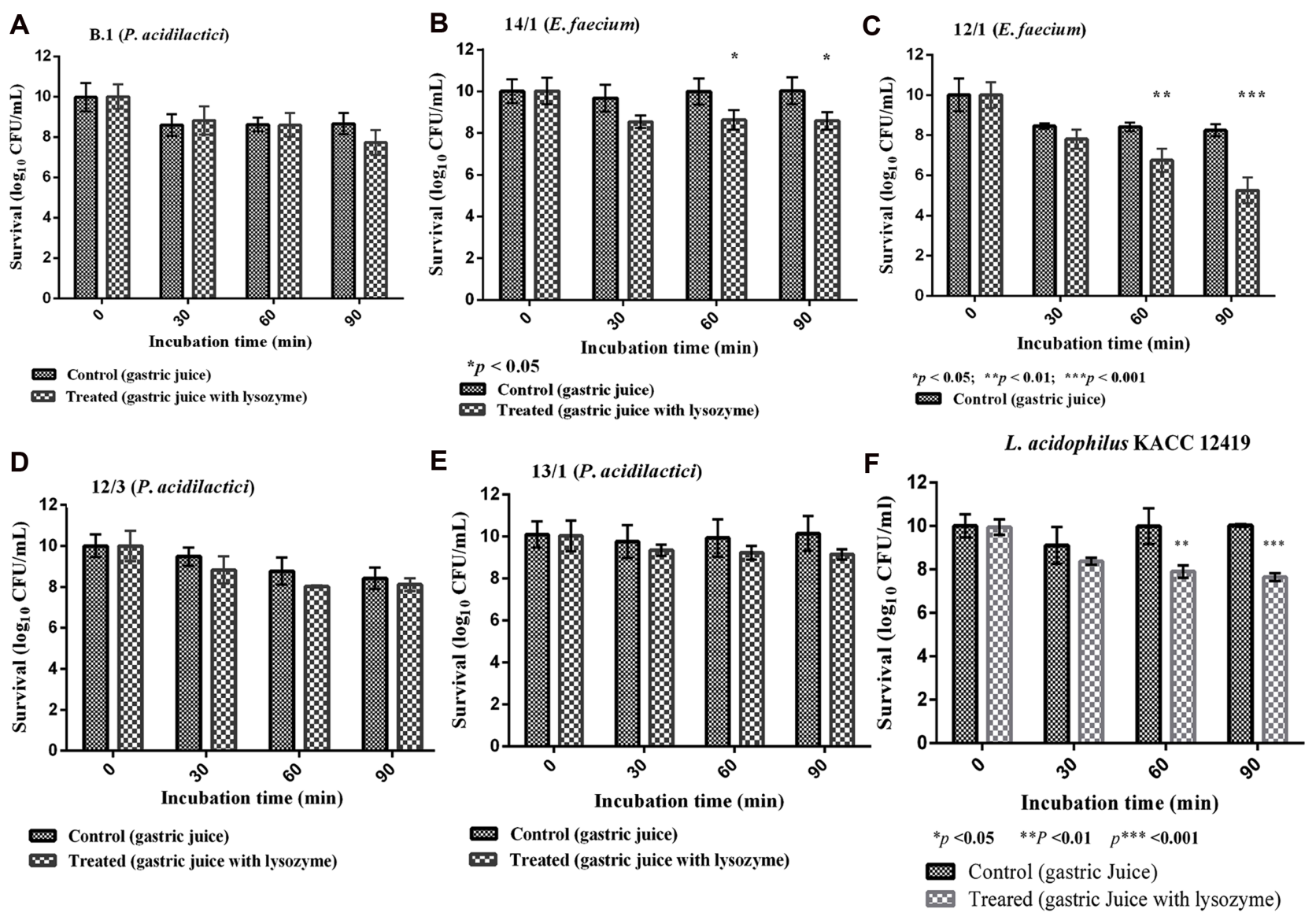

Fig. 3. Survival of isolated probiotic candidates comparing with Lactobacillus acidophilus KACC 12419 in simulated gastric juice (pH 2.0); without lysozyme \& with lysozyme. The results are expressed as mean \pm SD of three independent experiments. Statistical significance was determined with the help of Two way ANOVA. ${ }^{*} p<0.05,{ }^{* *} p<0.01,{ }^{* * *} p<0.001$.

selected LAB isolates were moderately tolerant up to $0.4 \%$ phenol Isolate $13 / 1$ and B1 retained the highest cell concentration $(\mathrm{OD}=0.189$ and 0.182 , respectively at $600 \mathrm{~nm}$ ) in the presence of $0.4 \%$ phenol concentration. In contrast, E. faecium (12/1 and 14/1) was the least than the $P$. acidilactici. It is agreed that the probiotic bacteria which can resist $0.4 \%$ phenol in vivo can be able to survive in the intestinal tract [23]. In our study, $P$. acidilactici \& E. faecium were moderately tolerant to phenol, though the growth of $P$. acidilactici is still high in the presence of $0.4 \%$ phenol concentration (Fig. 2B).

Adhesion assay to the ileum mucosal epithelium. Isolated strains showed acceptable adhesion ability with mucosal epithelial cells within $90 \mathrm{~min}$. Their adhesin ability increased over time; after $90 \mathrm{~min}$ of incubation, all the isolates adhere around $2 \log \mathrm{CFU} / \mathrm{cm}^{2}$. The mean counts of 12/3 isolates were $0,1.82,2.093$, and $2.347 \mathrm{log}$ $\mathrm{CFU} / \mathrm{cm}^{2}$ following the exposure time at $0,30,60$ and $90 \mathrm{~min}$, and the count was significantly high $(p<0.05)$ at 90 min compared to 0 min than other isolates. Furthermore, the isolate 12/1 showed the lowest cell count with mean bacterial count were $0,1.092,1.858$ and $1.986 \log \mathrm{CFU} / \mathrm{cm}^{2}$ (Fig. 2C).

In vitro gastrointestinal transit tolerance assay. Hydrochloric acid of human stomach degrades or dissolved all sorts of macromolecules e.g. proteins, lipid etc including bacteria regardless of beneficial or pathogenic. P. acidilactici (B.1, 12/3, 13/1) isolates have no impact on the growth in the gastric juice treatment with lysozyme $(p>$ 0.05 ; Figs. 3A, 3D and 3E). In contrast, the mean counts of $12 / 1$ isolates were $10.01,8.45,8.42$ and $8.24 \log \mathrm{CFU} /$ $\mathrm{ml}$ in gastric juice, while $10.00,7.80,6.75$, and $5.26 \mathrm{log}$ 
Table 3. Antibiotics susceptibility assay for probiotic candidates.

\begin{tabular}{|c|c|c|c|c|c|c|c|}
\hline \multirow[b]{2}{*}{ Antibiotics } & \multirow[b]{2}{*}{$\begin{array}{c}\text { Disc } \\
\text { content }\end{array}$} & \multicolumn{6}{|c|}{ Diameter of inhibition zone (mm) } \\
\hline & & B1 & $12 / 1$ & $12 / 3$ & $13 / 1$ & $14 / 1$ & $\begin{array}{l}\text { Lactobacillus } \\
\text { acidophilus } \\
\text { KACC } 12419\end{array}$ \\
\hline Amikacin & $30 \mu \mathrm{g}$ & $20(l)$ & $21(S)$ & $22(S)$ & $19(\mathrm{l})$ & $25(S)$ & $16(l)$ \\
\hline Vancomycin & $30 \mu \mathrm{g}$ & $19(\mathrm{l})$ & $18(I)$ & $18(\mathrm{l})$ & $17(I)$ & $17(\mathrm{l})$ & $11(\mathrm{R})$ \\
\hline Gentamycin & $10 \mu \mathrm{g}$ & $22(\mathrm{~S})$ & 24(S) & $21(\mathrm{~S})$ & $22(\mathrm{~S})$ & $24(S)$ & $10(\mathrm{R})$ \\
\hline Chloramphenicol & $30 \mu \mathrm{g}$ & $21(\mathrm{~S})$ & $21(\mathrm{~S})$ & $23(\mathrm{~S})$ & $21(\mathrm{~S})$ & $22(\mathrm{~S})$ & $22(\mathrm{~S})$ \\
\hline Nitrofurantion & $300 \mu \mathrm{g}$ & $17(l)$ & $16(l)$ & $16(l)$ & $16(l)$ & $18(l)$ & $16(l)$ \\
\hline Streptomycin & $10 \mu \mathrm{g}$ & $18(l)$ & $21(\mathrm{~S})$ & $19(l)$ & $20(l)$ & $22(\mathrm{~S})$ & $11(\mathrm{R})$ \\
\hline Ceptriaxone & $30 \mu \mathrm{g}$ & $20(l)$ & $19(\mathrm{l})$ & $18(\mathrm{I})$ & $20(\mathrm{l})$ & $20(l)$ & $18(\mathrm{I})$ \\
\hline Norfloxacin & $30 \mu \mathrm{g}$ & $24(S)$ & $20(l)$ & $22(\mathrm{~S})$ & $21(\mathrm{~S})$ & $20(l)$ & $17(I)$ \\
\hline Azithromycin & $15 \mu g$ & $21(S)$ & $18(\mathrm{l})$ & $20(S)$ & $21(\mathrm{~S})$ & $19(\mathrm{l})$ & $21(S)$ \\
\hline Cefaclor & $30 \mu \mathrm{g}$ & $17(I)$ & $15(\mathrm{R})$ & $17(I)$ & $16(l)$ & $15(\mathrm{R})$ & $12(\mathrm{R})$ \\
\hline Ciprofloxacin & $10 \mu \mathrm{g}$ & $21(S)$ & $22(S)$ & $21(S)$ & $22(\mathrm{~S})$ & $23(S)$ & $11(\mathrm{R})$ \\
\hline
\end{tabular}

$\mathrm{R}$ (resistant) $=\leq 15 \mathrm{~mm}$

I (intermediate) $=16-20 \mathrm{~mm}$

$\mathrm{S}$ (susceptible) $=\geq 21 \mathrm{~mm}$

$\mathrm{CFU} / \mathrm{ml}$ were achieved by applying treatments of lysozyme with gastric juice after $0,30,60$ and 90 min exposure time, compared to control group at $60 \mathrm{~min}$ and 90 min of exposure time (Fig. 3C). While approximate mean counts of 10.02, 8.54, 8.63 and $8.59 \mathrm{log} \mathrm{CFU} / \mathrm{ml}$ were achieved from 10.00, 9.68, 9.99 and $10.03 \mathrm{log} \mathrm{CFU} / \mathrm{ml}$ counts in gastric juice by treating with lysozyme after 0 , 30,60 and 90 min exposure time for the another isolate $14 / 1$, had a significant effect compared to control after $60 \mathrm{~min}$ and $90 \mathrm{~min}$ of exposure time ( $p>0.05$; Fig. 3B). In our study, both $P$. acidilactici and E. faecium demonstrated notable tolerance to acidic $\mathrm{pH} 2.0$ following the $90 \mathrm{~min}$ of exposure (Fig. 3). The reasonable cause can be demonstrated as the absence of the influence of dietary and nonacidic constituents of gastric secretion on probiotic survival [22]. Therefore, gastric juice survivability assay with lysozyme was further conducted. The growth of the isolates decreased during incubation with the presence of lysozyme. P. acidilactici was able to maintain a good growth in the presence of lysozyme and the reduction of increase ranged from 0.1 to $0.5 \mathrm{log}$ after 90 min of incubation (Fig. 3A, 3D, 3E). This result is supported by the previous study of Anadon et al. [38]. On the other hand, isolate $E$. faecium reduced their growth in the presence of lysozyme after $60 \mathrm{~min}$ and $90 \mathrm{~min}$ of exposure and the 18 reductions ranged from 0.5 to
$1.5 \log$ (Fig. 3B, 3C). ANOVA showed that the reduction was significant $(p<0.05)$ for $E$. faecium. However, differences in cell wall structures and layers may be attributed to the variations in lysozyme resistance of isolates. Thus, we conclude that all the five isolates succeeded the in vitro gastrointestinal transit tolerance assay.

Antibiotic susceptibility test. Multiple resistance patterns of antibiotics were observed for the all tested isolates. All the tested isolates were sensitive or moderate susceptible, except isolates $12 / 1$ and $14 / 1$, which exhibited resistance to Cefaclor $(30 \mu \mathrm{g})$ (Table 3$)$.

The results demonstrated the potential probiotic abilities of $P$. acidilactici and E. faecium strains isolated from goat milk and yogurt in Jashore, Bangladesh. These sequenced LAB strains are suitable for field trial as food and/or feed supplement for both animals and humans. Furthermore, the antagonistic properties demonstrated by these LAB strains against major foodborne zoonotic pathogens show their relevance in the control and prevention of enteric pathogens.

\section{Acknowledgment}

This research has been financed by the Bangladesh Academy of Science under BAS-USDA program code no. LSC 33. 


\section{Conflict of Interest}

The authors have no financial conflicts of interest to declare.

\section{References}

1. FAO/WHO (Food and Agriculture Organization of the United Nations WHO. 2002. Joint FAO/WHO Working group report on drafting guidelines for the evaluation of probiotics in food London, Ontario, Canada.

2. Bhardwaj A, Kapila S, Mani J, Malik R. 2009. Comparison of susceptibility to opsonic killing by in vitro human immune response of Enterococcus strains isolated from dairy products, clinical samples and probiotic preparation. Int. J. Food. Microbiol. 128: 513515.

3. Moroni O, Kheadr E, Boutin Y, Lacroix C, Fliss I. 2006. Inactivation of adhesion and invasion of food-borne Listeria monocytogenes by bacteriocin producin Bifidobacterium strains of human origin. Appl. Env. Microbiol. 72: 6894-6901.

4. Souza G, Ferrari S, Daiane C, Akmida L, Fatima K, Costa M, et al. 2013. Microbiological and physical-chemical profile of goat milk in the semiarid region of the San Francisco valley. Vet. Not. 19: 1422.

5. Tripathi M, Giri S. 2014. Probiotic functional foods: Survival of probiotics during processing and storage. J. Funct. Foods. 9: 225241.

6. Jayamanne V, Adams M. 2006. Determination of survival, identity, and stress resistance of probiotic bifidobacteria in bioyoghurts. Lett. Appl. Microbiol. 42: 189-194.

7. Braïek OB, Ghomrassi H, Cremonesi P, Morandi S, Fleury Y, Chevalier $\mathrm{P}$, et al. 2017. Isolation and characterization of an enterocin Pproducing Enterococcus lactis strain from a fresh shrimp (Penaeus vannamei). Antonie. Van. Leeuwenhoek 110: 771-786.

8. M'hir S, Minervini F, Cagno RD, Chammem N, Hamdi M. 2011. Technological, functional and safety aspects of enterococci in fermented vegetable products: a mini-review. Ann. Microbiol. 62: 469-481.

9. Ben Braïek O, Ghomrassi H, Cremonesi P, Morandi S, Fleury Y, Le Chevalier $P$, et al. 2017. Isolation and characterisation of an enterocin P-producing Enterococcus lactis strain from a fresh shrimp (Penaeus vannamei). Antonie Van. Leeuwenhoek 110: 771786.

10. Mehta R, Arya R, Goyal K, Singh M, Sharma AK. 2013. Bio-preservative and therapeutic potential of pediocin: recent trends and future perspectives. Recent Pat. Biotechnol. 7: 172-178.

11. Kolida S, Saulnier D, Gibson G. 2006. Gastrointestinal microflora: Probiotics. Adv. Appl. Microbiol. 59: 187-219.

12. Yadav R, Puniya A, Shukla P. 2016. Probiotic properties of Lactobacillus plantarum RYPR1 from an indigenous fermented beverage raabadi. Front. Microbiol. 7: 1683.

13. Yu B, Liu R, Hsiao F, Chiou P. 2008. Evaluation of Lactobacillus reuteri Pg4 strain expressing heterologous $\beta$-glucanase as a probiotic in a barley-base poultry diet. Animal. Feed. Sci. Technol. 141:
82-91.

14. Rajoka MR, Shi J, Zhu J, Shao D, Huang Q, Yang H, Jin M. 2017. Capacity of lactic acid bacteria in immunity enhancement and cancer prevention. App. Microbiol. Biotechnol. 101: 35-45.

15. Angmo K, Kumari A, Savitri, Bhalla TC. 2016. Probiotic characterization of lactic acid bacteria isolated from fermented foods and beverage of Ladakh. LWT - Food. Sci. Technol. 66: 428-435.

16. Larkin M, Blackshields G, Brown N, Chenna R, Mc-Gettigan P, McWilliam H, et al. 2007. Clustal W and Clustal X version 2.0. Bioinformatics (Oxford, England). 23: 2947-2948.

17. Tamura K, Dudley J, Nei M, Kumar S. 2007. MEGA4: Molecular Evolutionary Genetics Analysis (MEGA) software version 4.0. Mol. Biol. Evol. 24:1596-1599.

18. Tulumoglu S, Kaya H, Simsek O. 2014. Probiotic characteristics of Lactobacillus fermentum strains isolated from tulum cheese. Anaerobe 30: 120-125.

19. Ramos C, Thorsen L, Schwan R, Jespersen L. 2013. Strain-specific probiotics properties of Lactobacillus fermentum, Lactobacillus plantarum and Lactobacillus brevis isolates from Brazilian food products. Food. Microbiol. 36: 22-29.

20. Huang Y, Wang J, Wang F, Wu Y, Sui L, Yang, Wang Z. 2013. Lactobacillus plantarum strains as potential probiotic cultures with cholesterol-lowering activity. J. Dairy. Sci. 96: 2746-2753.

21. Chettri R, Tamang J. 2014. Functional properties of tungrymbai and bekang, naturally fermented soybean foods of North East India. Int. J. Ferm. Foods. 3: 87-103.

22. Abbasiliasi S, Shun TJ, Ibrahim T, Ramanan R, Vakhshiteh F, Mustafa S. 2012. Isolation of Pediococcus acidilactici Kp10 with ability to secrete bacteriocin-like inhibitory substance from milk products for applications in food industry. BMC. Microbiol. 12: 260.

23. Aswathy R, Ismail B, John P, Nampoothiri K. 2008. Evaluation of the probiotic characteristics of newly isolated lactic acid Bacteria. Appl. Biochem. Biotechnol. 10: 8183-8186.

24. Flanagan R, Neal-McKinney J, Dhillon A, Miller W, Konkel M. 2009. Examination of Campylobacter jejuni putative adhesins leads to the identification of a new protein, designated FlpA, required for chicken colonization. Infect. Immun. 77: 2399-2407.

25. Huang Y, Adams M. 2004. In vitro assessment of the upper gastrointestinal tolerance of potential probiotic dairy propionibacteria. Int. J. Food. Microbiol. 91: 253-260.

26. Vuyst LD, Moreno MF, Revets H. 2003. Screening for enterocins and detection of hemolysin and vancomycin resistance in enterococci of different origins. Int. J. Food. Microbiol. 84: 299318.

27. García V, Rovira S, Boutoial K, López MB. 2014. Improvements in goat milk quality: A review. Small. Rumi. Res. 121:51-57.

28. de Moraes GMD, de Abreu LR, do Egito AS, Salles HO, da Silva LMF, Nero LA, et al. 2017. Functional Properties of Lactobacillus mucosae Strains Isolated from Brazilian Goat Milk. Prob. Antimicrob. Proteins. 9: 235-245.

29. Argyri A, Zoumpopoulou G, Karatzas K, Tsakalidou E, Nychas G, Panagou $E$, et al. 2013. Selection of potential probiotic lactic acid bacteria from fermented olives by in vitro tests. Food Microbiol. 
33: 282-291

30. Erkkilä $S$, Venäläinen $M$, Hielm $S$, Petäjä $E$, Puolanne $E$, MattilaSandholm T. 2000. Survival of Escherichia coli O157:H7 in dry sausage fermented by probiotic lactic acid bacteria. J. Sci. Food. Agri. 80: 2101-2104.

31. Pisano MB, Casula M, Corda A, Fadda ME, Deplano M, Cosentino S. 2008. In vitro probiotic characteristics of lactobacillus strains isolated from fiore sardo cheese. Ita. J. Food. Sci. 20: 505-516.

32. Bustos AY, Saavedra L, de Valdez GF, Raya RR, Taranto MP. 2012. Relationship between bile salt hydrolase activity, changes in the internal $\mathrm{pH}$ and tolerance to bile acids in lactic acid bacteria. Biotechnol. Lett. 34: 1511-1518.

33. Oh YJ, Jung DS. 2015. Evaluation of probiotic properties of Lactobacillus and Pediococcus strains isolated from Omegisool, a traditionally fermented milletalcoholic beverage in Korea. LWT. Food. Sci. Technol. 63: 437-444.

34. Coulibaly I, Robin Dubois D, Destain J, Philippe T. 2008. Characterization of lactic acid bacteria isolated from poultry farms in Senegal. Afr. J. Biotechnol. 7: 2006-2012.
35. Hoque MZ, Akter F, Hossain KM, Rahman MSM, Billah MM, Islam KMD. 2010. Isolation, identification and analysis of probiotic properties of Lactobacillus Spp. from selective regional yoghurts. World. J. Dairy. Food. Sci. 5: 39-46.

36. Pundir RK, Rana S, Kashyap N, Kaur A. 2013. Probiotic potential of lactic acid bacteria isolated from food samples: an in vitro study. J. Appl. Pharm. Sci. 3: 85-93.

37. Ahmed T, Kanwal R, Ayub N. 2006. Influence of temperature on growth pattern of Lactococcus lactis, Streptococcus cremoris and Lactobacillus acidophilus isolated from camel milk. Biotechnology 5: 481-488.

38. Anadon A, Martínez-Larrañaga MR, Aranzazu Martínez M. 2006. Probiotics for animal nutrition in the European Union. Regulation and safety assessment. Regul. Toxicol. Pharmacol. 45: 91-95.

39. Reuben, RC, Roy PC, Sarkar SL, Rubayet-UI Alam, Jahid IK. 2019. Isolation, characterization, and assessment of lactic acid bacteria toward their selection as poultry probiotics. BMC Microbiol. 19: 253. 